
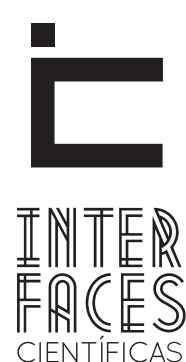

HUMANAS E SOCIAIS

ISSN IMPRESSO 2316-3348

E-ISSN 2316-3801

DOI-10.17564/2316-3801.2018v7n1p107-118

\title{
MULHERES NO CÁRCERE: BREVES REFLEXÕES SOBRE O SISTEMA PUNITIVO EM SERGIPE E OS DESAFIOS DA REINSERCÃ̃O SOCIAL
}

\author{
WOMEN IN PRISON: BRIEF REFLECTIONS ABOUT THE PUNITIVE SYSTEM IN SERGIPE AND THE CHALLENGES OF SOCIAL REINTEGRATION \\ MUJERES EN EL CÁrCEL: BREVES REFLEXIONES SOBRE EL SISTEMA PUNITIVO EN SERGIPE Y LOS DESAFíOS DE LA REINSERSIÓN SOCIAL
}

Juliana Vital Rosendo ${ }^{1}$

Grasielle Borges Vieira de Carvalho ${ }^{3}$
João Luciano Marques dos Santos Mota²

Liziane Paixão Silva Oliveira

\section{RESUMO}

0 artigo visa discutir a problemática em torno do encarceramento feminino, direcionando o olhar para a realidade encontrada no estado de Sergipe, tendo por embasamento os dados obtidos por meio do projeto de pesquisa "Mulheres Encarceradas: uma análise processual do Garantismo Penal no Presídio Feminino de Sergipe", desenvolvido no Presídio Feminino do estado entre os meses de março/2016 a fevereiro/2017. 0 trabalho discute pontos voltados a questões como as múltiplas punições sofridas pelas mulheres que estão em situação de cárcere; a possibilidade do crime de tráfico de drogas, ser caracterizado como o principal fator do encarceramento feminino; além de analisar qual seria a realidade enfrentada por essas mulheres na vida pós-cárcere na tentativa de reinserção social e superação do estigma deixado pela inserção no sistema prisional.

\section{PALAVRAS-CHAVE}

Encarceramento. Mulheres. Sergipe. 


\section{ABSTRACT}

The article aims to discuss the problematic around the female imprisonment, focusing on the reality found in the state of Sergipe, having as embassy the data obtained through the research project "Women in carcerated: a procedural analysis of the criminal guarantism in the Female Prison of Sergipe ", developed in the state prison between March/2016 and February/2017. This paper discusses issues related to multiple punishments suffered by women who are in prison; a possibi-

\section{RESUMEN}

El artículo apunta a discutir las problemáticas en torno al encarcelamiento femenino, dirigiendo la mirada a la realidad encontrada en el estado de Sergipe, teniendo por base los datos obtenidos por medio del proyecto de investigación “Mujeres Encarceladas: un análisis procesal del Garantismo Penal en la Presidencia Femenina en Sergipe”, desarrollado en la Presidencia Femenina del estado entre los meses de marzo/2016 a febrero/2017. El trabajo discute puntos dirigidos a cuestiones como las múltiples sanciones sufridas por las mujeres que están en situación de cárcel; lity of drug trafficking crime as the main factor of female incarceration; in addition to analyzing the reality faced by those women after leaving the prison system by attempting social reintegration and overcoming the stigma left by insertion into the prison system.

\section{KEYWORDS}

Incarceration. Women. Sergipe. la posibilidad del crimen de tráfico de drogas ser caracterizado como el principal factor del encarcelamiento femenino; además de analizar cuál sería la realidad enfrentada por esas mujeres en la vida poscárcel en el intento de reinserción social y superación del estigma dejado por la inserción en el sistema penitenciario.

\section{PALABRAS-CLAVE}

Encarcelamiento. Mujeres. Sergipe. 


\section{INTRODUÇÃO}

Do global ao local, é certo que ainda no surgimento da execução da pena privativa de liberdade, fez-se por observável destacada preocupação em separar homens e mulheres. 0 intrigante, porém, aponta para a suficiência dos fundamentos empreendidos na construção de tal ideal.

No Brasil, esteve como argumento fundante para cisão e colocação geograficamente distante entre estabelecimentos destinados aos sexos opostos, à precaução em impedir suposta influência nociva por parte das mulheres sobre os homens. Ainda erguendo a presunção de que estaria na pessoa destas, a possibilidade em despertar no ser masculino seus mais primitivos instintos e, por conseguinte, ampliação do sofrimento inerente à abstinência imposta pela custódia (BRITTO apud SOARES; ILGENFRITZ, 2002, p. 57).

Há que se perceber com isso, a problemática atinente ao supedâneo histórico e social, utilizado até então para impor ao Estado segregação em moldes diversos e não mais tardar para construção de estabelecimentos prisionais femininos. Nunca se esteve por parâmetro à dignidade da mulher, provável cautela pelas questões biológicas ou de gênero, pelo contrário, insurge mais uma vez como objetivo a proteção ao homem e aos "bons costumes".

Em questões numéricas, resta patente que a população carcerária feminina é significativamente menor, todavia, está contido neste motivo, fator que potencializa e conduz para ainda maior delicadeza no que atine ao encarceramento feminino, posto que, são limitadas as pesquisas neste assunto, de igual maneira dispêndio de tempo e investimentos por parte do Estado.

Dessa forma, o artigo tem como base o projeto de pesquisa desenvolvido na Universidade Tiradentes, intitulado "Mulheres Encarceradas: uma análise processual do Garantismo Penal no Presídio Feminino de Sergipe". A pesquisa teve como objetivo principal analisar os processos penais em fase de execução (dispostos na $7^{\circ}$ Vara das Execu- ções Criminais), os quais tem como protagonista a mulher, sinalizando as garantias asseguradas ao gênero no estado de Sergipe.

A partir da análise dos processos foi possível obter informações a respeito do "perfil" da mulher encarcerada em Sergipe, bem como quais os benefícios e garantias concedidos processualmente a elas por meio da Defensoria Pública ou defensor privado. Por meio do desenvolvimento da pesquisa, foram ainda, verificados pontos relativos a alguns institutos da execução penal, a exemplo da progressão de regime, liberdade condicional e autorização de saída, correlacionando-os com a teoria do Garantismo Penal. E por fim, verificou se a questão de gênero na fase de execução penal está sendo respeitada no estado de Sergipe, de forma processual.

A metodologia utilizada para o desenvolvimento da pesquisa teve por embasamento dois métodos, o bibliográfico e empírico. 0 método bibliográfico possibilitou uma investigação acerca dos postulados teóricos do Garantismo Penal e da situação da mulher encarcerada em todo Brasil. O levantamento ocorreu por meio da análise de documentos/relatórios oficiais disponibilizados, teses, dissertações, artigos, que trabalham a temática em estudo etc.

No que compete ao método empírico, o estudo foi dividido em estatístico e tipológico. No primeiro, o levantamento ocorreu a partir da coleta de dados dos processos de execução penal dispostos na $7^{\circ}$ Vara das Execuções Criminais do estado de Sergipe. Com relação ao segundo, foram desenvolvidas análises das características essenciais do modelo Garantista, a partir das informações coletadas na pesquisa.

0 artigo estrutura-se em três tópicos, os quais visam discutir pontos como a múltipla punição sofrida pelas mulheres que estão em situação de cárcere; problematizar a ideia em torno do crime de tráfico de drogas e se seria este o principal fator do encarceramento feminino; e por fim, entender qual seria a realidade enfrentada por essas mulheres na vida pós-cárcere na tentativa de reinserção social e superação do estigma deixado pela inserção no sistema prisional. 


\section{MULHERES ENCARCERADAS: AMÚLTIPLA PUNIÇÃO}

A mulher, representando $6,4 \%$ da população prisional brasileira, ou seja, 37.380 encarceradas no universo do sistema penitenciário, vem ocupando a anos um lugar que era originalmente de pertença do sexo masculino ${ }^{5}$. E justamente por sair do meio social que the foi destinado, qual seja, o âmbito doméstico, quebrando, portanto, os paradigmas e regras impostas pela sociedade, o estigma sofrido por essa classe, é relativamente superior daquele destinado aos homens ${ }^{6}$.

Quanto mais a mulher se afasta dos papéis culturalmente destinados a ela, mais rígido se coloca o direito penal e menos benevolente se torna o judiciário. 0 controle social, e consequentemente o sistema penal não foram erigidos para as mulheres, "foi dirigido especificamente aos homens, enquanto operadores de papéis na esfera (pública) da produção material. O seu gênero, do ponto de vista simbólico, é masculino". A ideologia oficial do sistema reproduz a diferenciação social das qualidades e valores masculinos e femininos. (BARATTA, 1999, p. 46).

Estamos diante, portanto, de uma seletividade do sistema penal, o qual alimentado por uma sociedade patriarcal, mantém a ideia da mulher como um ser inferior ao homem, cujas práticas delituosas não são vistas da mesma forma. Ou seja, a mulher transgressora é vista por uma ótica diferente da direcionada ao homem ${ }^{7}$. Não havendo uma aceitação social àquela mulher que comete crimes, sendo

5 Entre os anos de 2000-2014, a população carcerária feminina cresceu $567 \%$, enquanto que na masculina houve um aumento de $220 \%$ (passando a totalizar em 2014, 542.407 homens encarcerados). Dados disponibilizados em: <http://www.justica.gov.br/seus-direitos/politica-penal/documentos/ relatorio-infopen-mulheres.pdf>. Acesso em: 10 abr. 2017.

6 Como aduz Zaffaroni (2000, p. 25): "O poder patriarcal (privado) controla as mulheres, crianças e velhos, enquanto o poder punitivo controla os homens". 7 Ainda em conformidade com Baratta (1999, p. 45): “A relação de condicionamento recíproco entre esta seletividade e a realidade social não é mensurável apenas com a escala das posições sociais e com a sua reprodução. A estrutura dos papéis nas duas esferas da divisão social de trabalho, quais sejam, a da produção material e a da reprodução, não é menos importante. É nesta diferenciação das esferas e dos papéis na divisão do trabalho que age a construção social dos gêneros. A sociedade patriarcal reservou, de forma ampla, o protagonismo da esfera produtiva aos homens e do círculo reprodutivo, às mulheres". ela alvo de uma estigmatização social e invisibilizada em âmbito social e familiar.

$\mathrm{Na}$ individualização da execução penal, o processo se repete. Ocorre que tanto a criminalidade quanto a prisão são esferas masculinas e as mulheres que ocupam esses espaços apropriam-se de uma masculinidade que não the pertence. Assim devem sofrer a correção pelo crime e pela conduta, devendo ser reeducados, a fim de formatarem-se ao padrão feminino "ideal”. (BUGLIONE, 2007, p. 151-153).

A mulher ampliou nas últimas décadas, portanto, sua participação no espaço social, o que pode representar uma das razões para o aumento da criminalidade feminina. Enquanto antes apenas os homens estavam além do âmbito doméstico e tinham, decorrentemente, mais oportunidades de praticar crimes, as mulheres, relegadas ainda a situações da vida privada e familiar, estavam em geral relacionadas apenas a ilícitos passionais, com baixíssimos índices de criminalidade (BIANCHINI, 2013).

As diversas violações ao gênero ${ }^{8}$ feminino que se encontra em situação de cárcere, ocorre nos mais diversos aspectos. No que compete ao seio familiar, essa mulher é em muitos casos esquecida. Ao contrário do encontrado nas penitenciárias masculinas, as visitas nos presídios femininos são raras, por motivos diversos, seja por outros entes familiares (a exemplo de maridos ou filhos) estarem presos ou por simplesmente não aceitarem a situação em que se encontram e decidem retirá-las de suas vidas.

A sociedade por sua vez, tende a segregá-la e dificultar a sua reinserção no meio social. Se as oportunidades destinadas a essas mulheres já eram escassas anteriormente ao encarceramento, pós-cárcere elas são ainda piores. São poucas as que conseguem o "perdão" social de forma a obter oportunidades para superar a situação de marginalidade na qual se encontravam.

O Estado pode ser caracterizado como o maior violador dos Direitos Humanos dessas mulheres. Pois,

8 "Gênero refere-se à institucionalização social das diferenças sexuais; é um conceito usado por aqueles que entendem não apenas a desigualdade sexual, mas muitas das diferenciações sexuais, como socialmente construídas" (OKIN, 2008, p. 306). 
é o grande responsável por não proporcionar meios educacionais, trabalhistas, de saúde, o que acaba por influenciar na sua inserção no mundo da criminalidade. Não são os únicos motivos, mas podem sim, ser considerados como fatores que influenciam. E tais violações persistem dentro do sistema carcerário.

Ao contrário do homem, a mulher possui especificidades que precisam ser respeitadas, como é o caso da maternidade no cárcere (já ingressam no sistema como mães ou dão à luz enquanto estão encarceradas); questões voltadas a higiene feminina, que requer um cuidado diferenciado; acesso a exames rotineiros, dentre outros. Onde muitas dessas mulheres encontram-se com idades entre 21 e 50 anos, conforme demonstrado no Gráfico 1 abaixo:

\section{Gráfico 1 - Faixa etária das apenadas}

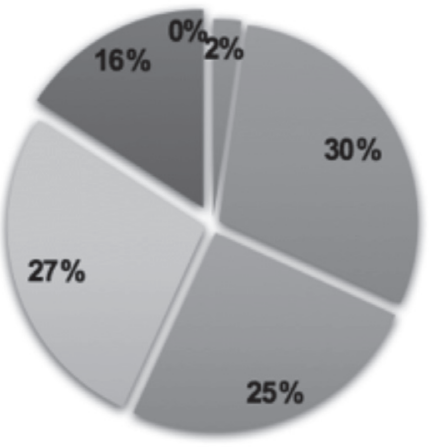

\section{$-18-20$ anos 41 - 50 anos}

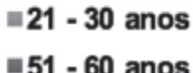

\section{$=31-40$ anos}

\section{Mais de 60 anos}

Fonte: Elaborado pelos Autores (2017)9.

Dentro de tantas problemáticas, é valido destacar que recentemente, mais especificamente no mês de abril de 2017, foi publicado o Decreto que institui um indulto de Dia das Mães. Para que sejam beneficiadas, essas mulheres devem atender alguns requisitos de forma cumulativa, como por exemplo, não estarem

90 gráfico foi elaborado pelos autores a partir dos dados dispostos no relatório final do projeto de pesquisa "Mulheres Encarceradas: uma análise processual do Garantismo Penal no Presídio Feminino de Sergipe”. Foram analisados 44 processos referentes ao total de mulheres em execução definitiva. respondendo ou terem sido condenadas pela prática de outro crime cometido mediante violência ou grave ameaça e não terem sido punidas com a prática de falta grave. Além de outros requisitos estabelecidos no artigo $1^{\circ}$ do referido Decreto ${ }^{10}$.

Segundo informações do Ministério da Justiça e Segurança Pública (2017), já foram concedidos aproximadamente 226 indultos, em estados como: Amazonas, Amapá, Bahia, Ceará, Espírito Santo, Mato Grosso do Sul, Paraná e Roraima. O indulto consiste em uma forma de perdão conferida pelo Presidente da República àqueles que cumprem com os requisitos para tal concessão, de forma a extinguir a punibilidade. 0 instituto do indulto está previsto no artigo 107, II, do Código Penal e nos artigos 187 a 193 da Lei de Execução Penal (Lei nº 7.210/84).

A partir do que foi apresentado é possível perceber que a penalização da mulher que comete um crime não está restrita a pena imposta pelo Estado e nem é completamente extinta após o seu cumprimento. Tal ação delituosa gera diversas ramificações, gerando consequências no âmbito familiar e

10 Art. $1^{\circ}[. .$.$] III - se enquadrem, no mínimo, em uma das seguintes hipóteses:$ a) mães condenadas à pena privativa de liberdade por crimes cometidos sem violência ou grave ameaça, que possuam filhos, nascidos ou não dentro do sistema penitenciário brasileiro, de até doze anos de idade ou de qualquer idade se pessoa com deficiência [...] que comprovadamente necessite de seus cuidados, desde que cumprido um sexto da pena; b) avós condenadas à pena privativa de liberdade por crimes cometidos sem violência ou grave ameaça, que possuam netos de até doze anos de idade ou de qualquer idade se pessoa com deficiência que comprovadamente necessite de seus cuidados e esteja sob a sua responsabilidade, desde que cumprido um sexto da pena; c) mulheres condenadas à pena privativa de liberdade por crimes cometidos sem violência ou grave ameaça, que tenham completado sessenta anos de idade ou que não tenham vinte e um anos completos, desde que cumprido um sexto da pena; d) mulheres condenadas por crime praticado sem violência ou grave ameaça, que sejam consideradas pessoa com deficiência [...] e) gestantes cuja gravidez seja considerada de alto risco, condenadas à pena privativa de liberdade, desde que comprovada a condição por laudo médico emitido por profissional designado pelo juízo competente; f) mulheres condenadas à pena privativa de liberdade não superior a oito anos, pela prática do crime previsto no art. 33, da Lei $n^{\circ} 11.343$, de 23 de agosto de 2006, e a sentença houver reconhecido a primariedade da agente, os seus bons antecedentes, a não dedicação às atividades criminosas e a não integração de organização criminosa, tendo sido aplicado, em consequência, o redutor previsto no $\S 40$ do referido artigo, desde que cumprido um sexto da pena; g) mulheres condenadas à pena privativa de liberdade não superior a oito anos por crime praticado sem violência ou grave ameaça, desde que cumprido um quarto da pena, se não reincidentes; ou h) mulheres condenadas à pena privativa de liberdade não superior a oito anos por crime praticado sem violência ou grave ameaça, desde que cumprido um terço da pena, se reincidentes. 
social, a partir da sua não aceitação. Por isso, é de fundamental importância tentar compreender os fatores que as levam a praticar tais ações e de que forma elas podem ser minimizadas.

\section{DROGAS X ENCARCERAMENTO FEMININO: SERIA ESSE O PRINCIPAL FATOR?}

Enquanto se faz por acompanhar significativas mudanças ao redor do mundo com relação ao controle das drogas ilícitas, a exemplo do Uruguai e os quatro estados americanos, Colorado, Washington State, Oregon e Alaska, que de alguma forma legalizaram o uso da canâbis, o Brasil signatário de todos os aparelhos repressivos internacionais, insiste num rígido sistema proibicionista (BOITEUX, 2015, p. 2).

0 grande problema está na falha para realização do que oficialmente se dispõe o uso do direito penal e tais métodos de interferência, não logrando êxito em sua proposta de diminuir produção e consumo as drogas ilícitas, por consequência proteção a saúde pública (BOITEUX, 2015, p. 2).

Em sentido contrário, a insistência no que denominado por estudiosos da temática como "guerra as drogas", acaba por atingir de forma drástica muitos indivíduos, apresentando-se hoje no Brasil como a maior causa do encarceramento feminino. Segundo dados do Informativo Penitenciário em edição especial as mulheres (DEPEN, 2014), 68\% das custodiadas em nível nacional respondem pelo crime de tráfico, possuem baixa escolaridade, estão inseridas numa classe social de baixo poder econômico, são jovens, mas com filhos e responsáveis pelo sustento familiar.

No estado de Sergipe, tomando por base o ano de 2016 e as 44 internas em execução definitiva no PREFEM, o crime de tráfico é o responsável pela reclusão de $43 \%$ destas (GRÁFICO 2), que sem maiores contrastes com a realidade dos outros entes federativos, apresentam por destaque o pouco estudo e exercício de trabalhos informais.
Gráfico 2 - Referente aos cinco crimes mais praticados

30

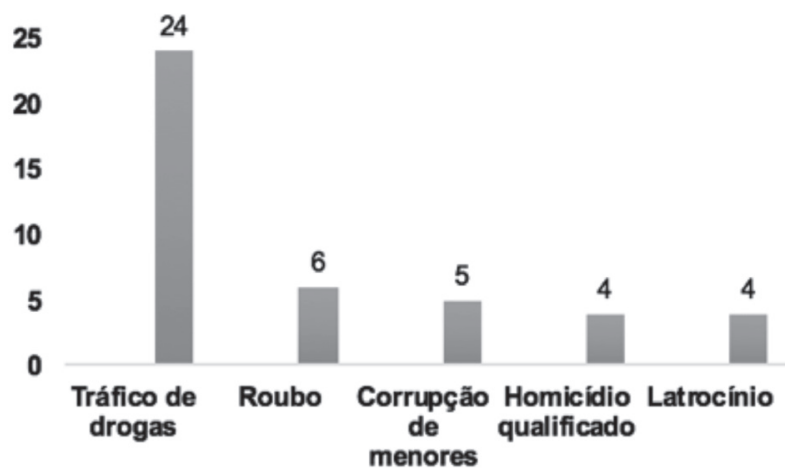

Fonte: Elaborado pelos Autores (2017) ${ }^{11}$.

Nesse sentido, faz-se por observar que além de ineficiente, a atual postura de proibição às drogas, tem tomado dimensões mais danosas e agressivas que o possível mal trazido pelas próprias substâncias. Corroborando com este entendimento tem se pronunciado Maria Lucia Karam (2016, p. 119):

\begin{abstract}
As convenções internacionais e leis nacionais que discriminatoriamente proíbem condutas de produtores, comerciantes e consumidores das arbitrariamente selecionadas drogas tornadas ilícitas ilegitimamente criam 'crimes sem vítimas', mas a proibição e sua guerra, como quaisquer outras guerras, são letais. A 'guerra às drogas' mata muito mais do que as drogas.
\end{abstract}

Em 2014 e 2015 alguns portais de notícia trouxeram informações que o Ministério Público de Minas Gerais, estaria recomendando a retirada de bebês de suas mães por serem estas usuárias de drogas. 0 portal R7 Notícias, na data de 23 de maio de 2015, expõe que na cidade de Belo Horizonte até aquele período, pelo menos 120 crianças teriam sido encaminhadas da maternidade a abrigos.

É com isso notável que o Brasil vem adotando medidas de austeridade e, mais uma vez, recai de forma

110 gráfico foi elaborado pelos autores a partir dos dados dispostos no relatório final do projeto de pesquisa "Mulheres Encarceradas: uma análise processual do Garantismo Penal no Presídio Feminino de Sergipe”. Foram analisados 44 processos referentes ao total de mulheres em execução definitiva. 
dúplice sobre a mulher os reflexos desta violência. Contudo, há que se trazer por resistência e questionamento as bases do Estado democrático de direito e seu papel enquanto garantidor da autodeterminação de seu povo.

Como já visto, a política criminal direcionada às drogas sempre se mostrou severa, dentro desse ideal o tráfico recebe equiparação a crime hediondo, restando com isso, à impossibilidade de qualquer benesse, partindo do Estado.

Por muitos anos, não esteve no interesse da política criminal adotada pelo país, maior apuração e individualização das condutas relativas à mulher e o tráfico. No contexto atual, mas respondendo a uma demanda histórica, houve a publicação de Decreto pela Presidência da República, vindo à situação de vulnerabilidade social das mulheres que estiveram a desempenhar pequenos papéis nas redes do tráfico.

É preciso reconhecer, de forma recente, o tamanho do impacto trazido pela decisão, que embora corresponda a um ato do poder executivo, terá reflexões diretas nos demais poderes.

É preciso que a consciência e delicadeza sejam ainda maiores quando estiver sobre o crivo dos julgadores uma mulher, mãe, filha, irmã, mantenedora do lar por meio dos esforços externos e internos. Urge como necessidade refinada ponderação, quando esteja por resposta ao crime de tráfico a imposição de uma pena restritiva de liberdade.

Sempre há que ser posto na balança pelo magistrado a suposta proteção à saúde pública, quando a ida ao cárcere custará à saúde pública dos seus custodiados e dependentes.

\section{VIDA PÓS-CÁRCERE E A SUPERAÇ̃̃O DO ESTIGMA SOCIAL}

A superação do estigma deixado pelo encarceramento não consiste em uma tarefa fácil, devido a tendência social de prolongar a punição. Punição esta que inicia pré-cárcere, a partir do momento em que uma determinada parcela da população tem suas oportunidades supridas em detrimento do outro, sur- tindo em efeitos como a falta de acesso ao sistema educacional, de saúde, mercado de trabalho - onde as oportunidades são escassas.

Essa situação agrava-se quando a situação da mulher encarcerada passa a ser analisada. 0 estigma enfrentado por ela é ainda maior do que o do homem, devido a crença social de que a mulher deve seguir os padrões impostos socialmente, de servir ao homem, aos filhos; competindo a ela o papel do "lar" e não de infringir normas estatais e se inserir no mundo do crime - até então pertencente ao homem. E caso isso aconteça, ela será esquecida, pela família, pela sociedade e pelo Estado. Visitas durante o cumprimento da pena, ocorrerão raramente; a sociedade julgará veemente essa mulher pela prática exercida; o Estado, negligenciará os cuidados a ela destinados na vida durante e pós-cárcere.

Tem-se, portanto, que a invisibilidade atribuída e a miopia adquirida pela sociedade frente ao problema carcerário, decorre na persistência da utilização da pena tão somente pelo prisma da retributividade (teoria absoluta), afastada, em tese, há muito tempo de nosso ordenamento jurídico. Tendo em vista que a carência de ações dificulta a possibilidade do trabalho ressocializador que fica prejudicado frente ao acúmulo de condições desfavoráveis a quem aplica e a quem se é aplicado. (MOTA; SODRÉ; ROSENDO; VIEIRA DE CARVALHO; 2016, p. 3217).

Por isso, torna-se de extrema relevância reavaliar de que maneira o encarceramento feminino vem sendo conduzido, pois estamos diante de seres humanos que um dia retornarão ao convívio em sociedade. É importante que a pena venha a ser cumprida como realmente deve, pelos prismas da retribuição, prevenção e principalmente da ressocialização. Oferecendo qualificação legítima para que não sofram mais que o necessário quando egressas, dando um tratamento digno quando internas, e observando suas individualidades de forma ampla, no que compete ao gênero, bem como em sentido estrito, enquanto pessoa (MOTA; SODRÉ; ROSENDO; VIEIRA DE CARVALHO, 2016, p. 3218).

Dessa forma, faz-se pertinente destacar dados obtidos durante o desenvolvimento da pesquisa no que 
compete ao quantitativo de detentas que obtiveram acesso ao ensino e quais os trabalhos desenvolvidos por ela antes de ingressarem ao sistema prisional. Conforme ficará demonstrado no Gráfico 3 a seguir:

Gráfico 3 - Grau de escolaridade

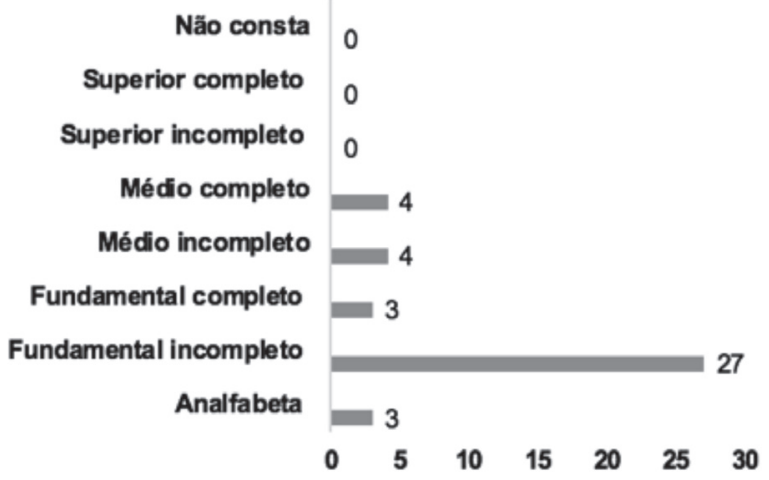

Fonte: Elaborado pelos Autores (2017) ${ }^{12}$.

O que se percebe a partir da análise dos dados trazidos acima, é que poucas detentas tiveram acesso ao sistema educacional e, em grande parte dos casos (aproximadamente 90\%), não conseguiram concluir sequer o ensino médio. Dentre os processos analisados, não ficou constatado nenhum caso de apenada que tenha iniciado ou concluído o ensino superior. Daí surge a importância de promover e fortalecer o ensino dentre do sistema carcerário, onde a educação à distância consiste em uma prática que pode contribuir no fortalecimento pessoal e profissional dessas mulheres.

A utilização do ensino à distância nos presídios é um mecanismo eficaz e de pouco custo por meio do qual os presos podem ter garantido o acesso à educação. Tendo em vista, a desestrutura e superlotação do sistema penitenciário brasileiro e a dificuldade da prestação dos serviços educacionais dentro do cárcere, onde podemos pontuar: falta de estrutura física ausência de salas de aulas, bibliotecas nos presídios,

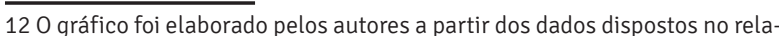
tório final do projeto de pesquisa "Mulheres Encarceradas: uma análise processual do Garantismo Penal no Presídio Feminino de Sergipe”. Foram analisados 44 processos referentes ao total de mulheres em execução definitiva. como também, a falta de profissionais da área da educação, com disponibilidade para trabalhar dentro das prisões. Sem falar da falta de segurança para estes profissionais. Diante disso, a possível implementação do ensino à distância dentro dos presídios abre um novo horizonte para a possibilidade de reinserção social pela educação e capacitação dos detentos (VIEIRA DE CARVALHO; ROSENDO; PEREIRA, 2016, p. 117).

Essa já é uma realidade nas práticas educacionais brasileiras. Mas no contexto do sistema carcerário, ainda consiste em um desafio a ser implementado como meio para facilitar a reinserção social da população carcerária. A parceria com as universidades públicas e privadas que já possuem esta dinâmica, consistiria em um grande avanço para oportunizar a educação e a capacitação para esta parcela da população brasileira que se encontra à margem da sociedade (VIEIRA DE CARVALHO; ROSENDO; PEREIRA, 2016, p. 123).

É válido ressaltar, no âmbito do sistema carcerário feminino sergipano, a parceria firmada com a Secretaria de Estado da Educação (SEED) que inseriu na unidade carcerária o Ensino para Jovens e Adultos (EJA), de forma a possibilitar para algumas internas a conclusão do ensino fundamental e médio, havendo até mesmo a realização do Exame Nacional do Ensino Médio para pessoas em condição de cárcere ${ }^{13}$.

Ainda com relação as parcerias firmadas, destacase a realização de cursos profissionalizantes, a exemplo do curso de cabelereiro oferecido pelo Serviço Nacional de Aprendizagem Comercial - SENAC Móvel, por meio do Programa Nacional de Acesso ao Ensino Técnico e Emprego (PRONATEC). O curso é desenvolvido por aulas teóricas, que incluem aprendizagem de organização de salão - forma de lidar com clientes e aulas práticas, como corte, escova, hidratação, relaxamento capilar, entre outras técnicas. Além do curso de manicure, o qual pode ser visto tanto sob o prisma do trabalho quanto um impulsor da autoestima, que é tão abalada no cárcere.

Cursos esses que coincidem em parte com algumas das profissões exercidas pelas apenadas antes

13 No ano de 2016, uma das internas obteve aprovação no curso de Dança na Universidade Federal de Sergipe. 
de ingressarem no sistema carcerário, conforme demonstrado no Gráfico 4 a seguir.

Gráfico 4 - Referente as profissões declaradas pelas internas

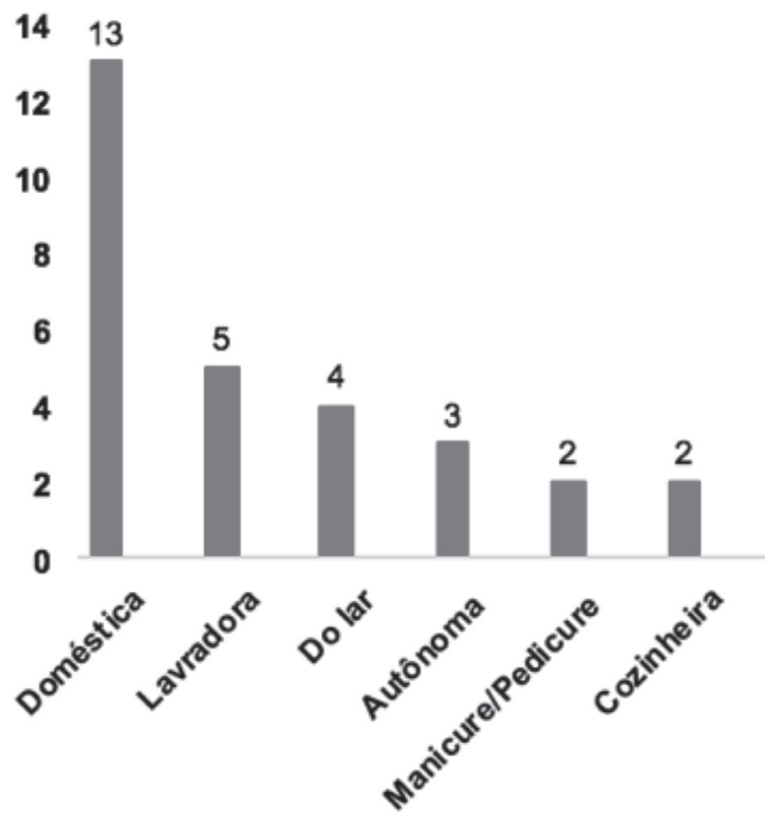

Fonte: Elaborado pelos Autores, 2017. ${ }^{14}$

Outro dado que merece ser destacado, compete ao percentual de detentas que obtiveram a remição da pena por meio do trabalho ou estudo. Ficou constatado que $63 \%$ das apenadas obtiveram a remição da pena por meio do labor, em sua maioria exercendo atividades voltadas para serviços gerais. Enquanto que 38,6\% conseguiram o direito à remição por horas estudadas.

Percebe-se que tais políticas consistem como instrumentos de extrema relevância para que sejam ofertadas dentro do sistema prisional oportunidades que proporcionem a essas mulheres condições de superar a situação de vulnerabilidade e estigmatização em

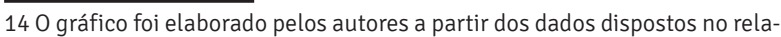
tório final do projeto de pesquisa "Mulheres Encarceradas: uma análise processual do Garantismo Penal no Presídio Feminino de Sergipe”. Foram analisados 44 processos referentes ao total de mulheres em execução definitiva. que se encontram, obtendo então meios de reconstruir suas vidas após o período de encarceramento.

\section{CONSIDERACÕ̃ES FINAIS}

É cogente olhar diferenciado para as dimensões que cercam a execução penal feminina. Por muito teve a (in)visibilidade ligação direta com as influências culturais, de forma involuntária e voluntária. 0 longo período dos cárceres mistos e com estruturas insalubres vivenciadas pelo Brasil teve forte reflexo no cenário estadual sergipano, que só se atentou para maximização dos direitos sociais e minimização da violência imanente à imposição da restrição de liberdade a uma mulher, no ano de 2010.

O fomento a pesquisas sobre a temática é de suma importância, é previsível que apontamentos em prol de melhorias só venham a surgir, por quem conheça a causa. Certo é que significativos avanços foram dados, mas não se pode discorrer sobre suficiência quando o parâmetro compreende exclusiva penitenciária feminina, em reduzidas condições físicas para aplicação do que é dito pela Lei de Execuções Penais, sobre legítimas práticas de reinserção social ou exercício de alguns direitos e institutos normativos.

Ademais, o esforço do profissional atuante na fase de execução penal é válido, mas insuficiente quando não corroborado por aqueles que estão a the anteceder. 0 viés punitivo, vingativo precisa ser posto de lado pelos julgadores da etapa de cognição. É preciso caráter crítico na atuação do legislador, bem como do poder executivo na preferência por políticas públicas preventivas e freios quando da construção das políticas criminais, consciente que Direito Penal não resolve problemas sociais.

\section{REFERÊNCIAS}

BARATTA, Alessandro. Paradigma do gênero: da questão criminal à questão humana. In: CAMPOS, Carmen (Org.). Criminologia e feminismo. Porto Alegre: Sulina, 1999. 
BRASIL. Decreto, de 12 de abril de 2017. Concede indulto especial e comutação de penas às mulheres presas que menciona, por ocasião do Dia das Mães, e dá outras providências. Diário Oficial [da] República Federativa do Brasil, Brasília-DF, 12 abr. 2017. Disponível em: <http://www.planalto.gov.br/ ccivil_03/_ato2015-2018/2017/dsn/Dsn14454.htm>. Acesso em: 29 maio 2017.

BRASIL. Ministério da Justiça e Segurança Pública. Depen divulga cartilha sobre o indulto especial concedido às mulheres presas. Disponível em: <http://www.justica.gov.br/seus-direitos/politicapenal/noticias-depen/depen-divulga-cartilha-sobreo-indulto-especial-concedido-as-mulheres-presas>. Acesso em: 1 jun. 2017.

BOITEUX, Luciana. Brasil: reflexões críticas sobre uma política de drogas repressiva: como políticas alternativas nacionais reforça a necessidade de mudanças no âmbito global. SUR: Revista Internacional de Direitos Humanos, v.12, n.21, p.1-6, ago. 2015.

BUGLIONE, Samantha. O dividir da execução penal. In: CARVALHO, Salo de (Org.). Crítica à execução penal. Rio de Janeiro: Lúmen Júris, 2007.

DEPEN. Ministério da Justiça. Levantamento nacional de informações penitenciárias - INFOPEN Mulheres - Junho de 2014. 2014. Disponível em: <http://www.justica.gov.br/seus-direitos/politicapenal/documentos/relatorio-infopen-mulheres.pdf>. Acesso em: 10 abr. 2017.

KARAM, Maria Lucia. Drogas: legalizar para garantir direitos humanos fundamentais. Revista da EMERJ, Rio de Janeiro, v.19, n.76, p.114-127, out-dez. 2016.

MENEZES, Enzo. Adoção obrigatória de bebês de usuárias de drogas provoca discussão em BH. R7, 25 maio 2015. Disponível em: <http://noticias. r7.com/minas-gerais/adocao-obrigatoria-debebes-de-usuarias-de-drogas-provoca-discussao- em-bh-23052015>.

Acesso em: 5 jun. 2017.

MOTA, João Luciano Marques dos Santo et al. A inserção da mulher no sistema carcerário e os Direitos Humanos: uma problemática jurídicosocial. In: DIAS, Alfrancio Ferreira; SANTOS, Elza Ferreira; CRUZ, Maria Helena Santana (Org.). Gêneros, feminismo, poderes e políticas públicas: investigações Contemporâneas. Campina Grande: Realize Eventos Científicos, 2016. p. 3209-3220. Disponível em: <http://editorarealize.com.br/ revistas/ebook_redor/trabalhos/gt12.pdf>. Acesso em: 28 mar. 2017.

OKIN, Susan Moller. Gênero, o público e o privado. 2008. Disponível em: <http://www.periodicos.ufsc. br/index.php/ref/article/view/9368/8618>.

Acesso em: 21 maio 2017.

SOARES, Bárbara Musumeci; ILGENFRITZ, Iara.

Prisioneiras: vida e violência atrás das grades. Rio de Janeiro: Garamond, 2002.

VIEIRA DE CARVALHO, Grasielle Borges; SANTOS, João Luciano Marques dos; SODRE, Emilly Samita da Anunciação. Mulheres na execução penal: uma análise do Garantismo Penal no Presídio Feminino de Sergipe. Relatório final - Projeto de Iniciação Científica. Universidade Tiradentes, Aracaju, 2017.

VIEIRA DE CARVALHO, Grasielle Borges et al. A educação à distância no sistema carcerário brasileiro: um novo caminho para o enfrentamento da desigualdade e pobreza. In: DUARTE, Clarice Seixa et al (Org.).

\section{Reflexões acadêmicas para superar a miséria e a} fome. Bauru: Canal 6, 2016. p.114-124. Disponível em: <https://comunicamack.files.wordpress.com/2016/08/ ebook-reflexc3b5es-acadc3aamicas-para-superar-amisc3a9ria-e-a-fome.pdf>. Acesso em: 1 jun. 2017.

ZAFFARONI, Eugenio Raúl. El discurso feminista y el poder punitivo. IN: BIRGIN, Haydée; BARATTA, 
Alessandro (Org.). Las trampas del poder punitivo: el género del derecho penal. Buenos Aires: Biblos, 2000.
Recebido em: 12 de Junho de 2017

Avaliado em: 19 de Março de 2018

Aceito em : 12 de Abril de 2018
1 Mestre em Direitos Humanos pela Universidade Tiradentes - UNIT/ SE; Bolsista CAPES/FAPITEC (2016-2018); Graduada em Direito pela Universidade Tiradentes - UNIT /SE; Integrante dos Grupos de Pesquisa de Execução Penal e Gênero, Família e Violência do Diretório de Pesquisa do CNPq. Advogada. E-mail: julianavrosendo@hotmail.com.

2 Bolsista PROBIC 2016/2017 do projeto “Mulheres Encarceradas: uma análise processual do Garantismo Penal no Presídio Feminino de Sergipe"; Integrante do Grupo de Pesquisa de Execução Penal do Diretório de Pesquisa do CNPq. E-mail: joaolucianomota@gmail.com.

3 Doutora em Direito Político e Econômico pela Universidade Presbiteriana Mackenzie em São Paulo/SP; Mestre em Direito Penal pela Pontifícia Universidade Católica de São Paulo - PUC/SP; Professora Adjunta e Pesquisadora do curso de Direito da Universidade Tiradentes - UNIT/SE; Líder dos Grupos de Pesquisa de Execução Penal e Gênero, Família e Violência do Diretório de Pesquisa do CNPq; Coordenadora do projeto "Mulheres Encarceradas: uma análise processual do Garantismo Penal no Presídio Feminino de Sergipe"; Advogada. E-mail: grasiellevieirac@gmail.com.

4 Doutora pela Universidade Aix-Marseille III, na França (2012); Mestre em Direito pela Universidade de Brasília - UNB (2006); Pós-graduada em Direito Ambiental - UniCEUB (2004); Professora da Universidade Tiradentes - UNIT; Bolsista de pós-graduação pela CAPES-FAPITEC (2017-2018); Pesquisadora do Instituto de Tecnologia e Pesquisa - ITP; Líder do Grupo de Pesquisa Novas Tecnologias e Direitos Humanos do Diretório de Pesquisa do CNPq. E-mail: liziane_paixao@unit.br. 
